\title{
“ESCRITOS ÍNTIMOS" E ESCRITA DE SI: POR ENTRE AS PÁGINAS E A VIDA DE ELZA FREIRE
}

\author{
NIMA IMACULADA SPIGOLON
}

Universidade Estadual de Campinas

RESUMO O trabalho integra o conjunto de fontes sobre Elza Freire, denominado "Escritos Íntimos", cujo recorte prioriza fragmentos de seus manuscritos num caderno de receitas. Há um arcabouço teóricometodológico com base na escrita de si - fundamental à formação e às práticas docentes, e como forma de resistência. Tais manuscritos traçam percursos seus e de Paulo Freire - seu esposo, como leituras possiveis do real entrecruzadas a uma memória individual e coletiva. A abordagem qualitativa vincula a eles, subjetividades e objetividades, dando visibilidade a ela, de modo indissociável das relações entre pensar, fazer e sentir nos tempos/lugares de professora. Processos de pesquisa revelam fontes primárias com complexas e minúsculas relações entre Elza - a mulher, o mundo e as páginas nas quais se arquivou parte de sua vida; eles aguçam evidências empíricas que provocam o enlaçamento, a busca e o encontro de/com uma mulher que talvez quisesse se prender ao anonimato ou se libertar na conquista de si mesma. 0 teor sensivel e o rigor acadêmico, ao abrir esse material, é como lidar com a alquimia de elementos potentes entremeados por temáticas igualmente fortes. Por fim, ao trazer fragmentos desses "Escritos Íntimos", a escolha é não decifrá-los e sim se aproximar dos sentidos e significados neles contidos.

Palavras-chave: Elza Freire. Paulo Freire. Escrita de si. Memória.

\section{ABSTRACT "INTIMATE WRITINGS" AND WRITTEN ABOUT YOURSELF: THROUGH THE PAGES AND THE LIFE OF ELZA FREIRE}

The paper integrates the set of sources on Elza Freire called "Intimates Writings" which prioritizes fragments of her manuscripts in a recipe book. There is a theoretical and methodological framework based on the written about yourself - essential for formation, teaching practices and as a form of resistance. Such manuscripts trace hers and Paulo Freire's routes - her husband, as real possible readings crisscrossing the individual and collective memory. The qualitative 
approach binds them, subjectivity and objectivity, giving visibility to her, in an indissociably manner of the relationship between thinking, doing and feeling in the days/places of teacher. Research processes reveal primary sources with complex and sensitive relationship between Elza - the woman, the world and the pages on which it filed part of her life, they sharpen empirical evidence that cause the bonding, the search and the meeting with/of a woman that might have wanted to attach to the anonymity or be freed in the conquest of herself. The sensitive content and academic rigor when opening this material is how to deal with the alchemy of powerful elements interspersed with equally strong themes. Finally, when bringing these fragments "Intimates Writings" the choice is not decipher them but approach senses and meanings contained therein.

Keywords: Elza Freire. Paulo Freire. Written about yourself. Memory.

"INTIMO DE LAS ESCRITURAS" Y SE ESCRIBE: A TRAVÉS DE LAS PÁGINAS Y LA VIDA DE ELZA FREIRE

El trabajo integra conjunto de fuentes de Elza Freire llama "Escritos Íntimos", que da prioridad a los fragmentos cortados de sus manuscritos en un libro de recetas. Existe un marco teórico y metodológico basado en la propia escritura - esencial para la formación, las prácticas de enseñanza y como una forma de resistencia. Tales manuscritos localización de un recorrido y Paulo Freire - su marido como lecturas reales posibles que cruzan la memoria individual y colectiva. El enfoque cualitativo los une, la subjetividad y objetividad, dando visibilidad a ella de manera indisociable la relación entre el pensar, hacer y sentir en los días/lugares de maestros. Procesos de investigación revelan fuentes primarias con relación compleja y sensible entre Elza - la mujer, el mundo y las páginas en el cual interpuso parte de su vida, que agudizan la evidencia empírica que causan la unión, la búsqueda y el encuentro de/con una mujer es posible que desee para insertarse en el anonimato o la liberación en la conquista de sí mismo. El contenido sensible y el rigor académico con la apertura de este material es cómo hacer frente a la alquimia de poderosos elementos intercalados con temas igualmente fuertes. Por último, para que estos fragmentos "Escritos Íntimos" la elección no es descifrarlos, pero sentidos de aproximación y significados contenidos en el mismo.

Palabras clave: Elza Freire. Paulo Freire. La própria escritura. Memoria. 


\section{Linhas iniciais}

Fiz o que queria, o que pensei, porque realmente fiz bem [...]

Elza Freire (1980, p. 200)

0 trabalho que orienta este texto é parte de um conjunto de fontes de pesquisa sobre Elza Freire, que venho reunindo desde 2006, denominados por mim como "Escritos Íntimos", e aqui prioriza seus manuscritos confinados num caderno de receitas.

É preciso deixar claro que ele compõe minhas primeiras incursões científicas na descrição, análise e interpretação de um material, que, cuidadosamente, venho abrindo, como parte de um processo, que é, por um lado, delicado, íntimo e pessoal e, por outro, portador de uma riqueza fenomenal de experiências, vivências e memórias.

Tem-se, como premissa básica, que os excertos retirados desse caderno de receitas e trazidos para as páginas do texto podem ser mais compreensiveis à medida que são referidos ao contexto em que se situam a sua criação e produção, respeitando-se a inexatidão de tempo/espaço e lugares.

Abrir e fechar, abrir de novo o caderno de receitas de Elza Freire, guardado por anos e anos, e rememorar o vivido, não foi e não é exatamente trazer os fatos tais como eles aconteceram e nem tampouco exercer a transcrição de letras; foi e está sendo um encontro com os sentidos atribuídos à experiência vivida, este mesmo, que me segura pela mão e me impulsiona a escrever, refletir e dialogar com autores que apontam a construção de um referencial, tendo como base a escrita de si

1 No Brasil, a tradição patriarcal influenciou as mulheres a adquirirem o sobrenome do marido, por ocasião do casamento civil. Elza Maia Costa Oliveira, ao casar-se com Paulo Réglus Neves Freire, assume juridicamente, pelo vínculo matrimonial, sua nova designação: Elza Freire. O casal passa a ser conhecido nacional e internacionalmente como: Elza Freire e Paulo Freire. Portanto, assim, me refiro a ela no texto.
- elemento fundamental para a formação, as práticas docentes e como forma de resistência. Foram, são e estão sendo os sentidos que me indicaram caminhos para vislumbrar outros novos sentidos, no tempo presente, num ir e vir contínuo que, ora deixava mais em evidência as objetividades, ora as subjetividades, capturadas por mim, na condição de pesquisadora, de professora e de mulher.

Ao trazê-los, de forma diluída, considero as impossibilidades de fazê-lo em sua totalidade. Tentei fazer com que eles fossem anunciados e o critério elegido para esse momento prioriza a Educação, entendida, aqui, como campo de formação e atuação de Elza Freire, caracterizado por atividades mediadoras, no seio da prática social e cultural, historicamente situadas. Como mediadora, a Educação remete às interfaces das demais manifestações da mulher, em termos de ação recíproca, crítica e emancipadora, bem como marca suas relações e outras questões que emergem.

Foi principalmente no interior dos "Escritos Íntimos", que Elza Freire, como os sujeitos e as narrativas, estes se apresentam a partir do que e como foi vivido e arquivado. Mas é também lá que estão as frestas para se refletir sobre "o que ordenamos, guardamos e classificamos" (ARTIÉRES, 1998).

O tema vincula-se a uma preocupação que é minha, desde que iniciei minhas atividades no campo da Educação de (Jovens) e Adultos, no final dos anos de 1990: o pensamento, a teoria e a prática político-pedagógica em Paulo Freire. Oficialmente, a pesquisadora surge com o Mestrado e, em seguida, o Doutorado, ambos na Faculdade de Educação na UNICAMP. ${ }^{2}$ Apenas quero assinalar que, hoje, ele continua se orientando a partir da concepção freireana de inacabado, incompleto e inconcluso.

Em dado momento, surge o interesse por Elza Freire, iniciado com as apropriações “par-

2 Consultar Spigolon (2009; 2014). 
ticulares" que faço das produções de Paulo Freire, pois, ao olhar mais atentamente para o conjunto de sua vida e obra, me identifico imediatamente com a presença e a participação dela, que me desperta de forma diferenciada e me provoca a questionar, por exemplo: quem é essa mulher? Quais as suas contribuições e influências na Educação, de modo geral, e na de Jovens e Adultos, de modo particular? Que participações teve no legado freireano? Desde então, venho me debruçando numa busca.

Busca eivada por objetividades: professora, pesquisadora, estudiosa de Paulo Freire, engajada na problemática da Educação de (Jovens) e Adultos etc., e por subjetividades: a empatia, a admiração, a paixão e a inquietação por Elza. Objetividades e subjetividades que não encobrem as questões fundantes das pesquisas, por mim já realizadas, e em realização.

Busca que assume várias dimensões e, ao ser acessada durante a pesquisa, traz "de um lado a dialética entre sujeito e objeto e de outro lado entre subjetividade e objetividade" (BRÜHL, p. 7). Estes aspectos são lados de um único processo social e, portanto, não podem ser dissolvidos artificialmente.

O tema é parte dos caminhos que percorri, em meus percursos profissionais, acadêmicos e pessoais, e que escolhi seguir, porque esse trabalho teórico-metodológico e crítico, em torno do professor, não se operou, em mim, apenas nas dimensões das ideias, dos conceitos, mas também se efetiva na prática e na reflexão sensivel sobre o político-pedagógico, fazendo parte dos processos de transformação da sociedade e das relações mediatizadas pelo meio no qual me identifico e atuo.

Desta forma, lançar mão da escrita de si e dos "Escritos Íntimos" de Elza Freire é lançarse na intenção de dar visibilidade aos movimentos, às vezes silenciosos e silenciados, que atravessam e forjam os percursos formativos -acadêmicos. Juntos, eles indicam possibilida- des de potencializar a discussão epistemológica acerca também da formação docente e do métier acadêmico.

\section{Elza Freire: entre o escrito e o dito}

Escolhi ser professora por mim mesma.

Elza Freire (1980, p. 202)

Elza Maia Costa Oliveira nasceu em junho de 1916, no Recife, Brasil. Filha de Alberto Melo Costa e Josefa Maia Costa Oliveira, teve dois irmãos: Elba Maia Dias Fernandes (Bila) e José de Melo Costa Oliveira (Zé de Melo).

Desde o início de seus estudos, obteve formação bastante sólida e diferenciada para a época. Na Escola da Professora Maria E. V. de Medeiros, próxima a sua residência, depois transferiu seus estudos para Olinda, matriculando-se na Academia Santa Gertrudes, escola confessional e tradicional, até retornar para Recife, onde cursou a Escola Normal, tida como referência, tornando-se professora em 1935. Em seguida, inscreve-se no Instituto Pedagógico, onde, de aluna, passa a professora, especializando-se em alfabetização. Frequentou escolas de referência e, ao longo da sua escolarização e formação, conviveu com importantes intelectuais e professores da época, o que influenciou decididamente o seu pensamento e a prática pedagógica, consolidando seu espírito crítico-solidário, que se desdobrou em prol das causas humanitárias.

Aprovada em concurso público para a rede estadual de Pernambuco, em 1943, exerceu o cargo de professora e diretora de escola, com destaque para as Escolas Mota e Albuquerque, Ageu Magalhães, Caio Pereira e Joaquim Nabuco.

É nesse período que conhece Paulo Freire, pois, com ele, foi ter aulas de gramática para o referido concurso. Casaram-se na primavera 
de 1944. A partir desse momento, por intermédio dela, acontece o encontro de Paulo Freire com a Educação. Então, juntos, passaram a desenvolver o trabalho político-pedagógico, notadamente no campo da Educação de Adultos e da Educação Popular. Aí teriam se fincado as bases para o Método Paulo Freire, que nos remete à gênese dessas atividades no Brasil, fundamentando uma Pedagogia da Convivên$\mathrm{cia}^{3}$ (SPIGOLON, 2009; 2014).

Nascem os filhos do casal Freire, as três Marias: Madalena (1946), Cristina (1947) e Fátima (1949), Joaquim (1956) e Lutgardes (1958).

Na década de 1950, Elza Freire foi uma das responsáveis pela inserção da arte-educação na escola pública do Recife. Foi precursora em práticas de ensino na formação de professores, bem como de educadores para atuação em Alfabetização de Adultos, trabalho que executou em Recife, Angicos e São Paulo (Vila Helena Maria), e em Brasília, no Plano Nacional de Alfabetização (PNA), quando Paulo Freire vai atuar no staff do Governo Goulart. 0 casal participa dos Movimentos de Educação de Base (MEB) e Cultura Popular (MCP), tendo sido Elza Freire a metodóloga das palavras geradoras e pioneira dos Círculos de Cultura, fundamentando e sistematizando, com Paulo Freire, as experiências de alfabetização para adultos conhecidas como "Método Paulo Freire".

Em decorrência do Golpe de 1964 e da ditadura instaurada, a família Freire é exilada. Paulo Freire depois da prisão e dos inquéritos sai primeiro, ainda em 1964, depois Madalena e, por fim, Elza Freire, com Cristina, Fátima, Joa-

3 Perspectiva formulada por mim (SPIGOLON, 2009; 2014), a partir das relações estabelecidas por Elza Freire e Paulo, no campo da Educação, após o casamento. Apresenta a convivência deles - que se encontram e se influenciam, mutuamente, também no campo da Educação, e, juntos, desenvolvem equações teóricas, metodológicas e práticas inovadoras e emancipadoras. É o processo político-pedagógico como possibilidade dialética e dialógica, capaz de impedir ou minimizar a dicotomia entre os sujeitos e a realidade existencial. Sigo trabalhando no seu aprofundamento. quim e Lutgardes. Elza Freire, Paulo e os cinco filhos se reúnem de novo, em Santiago, no Chile, em 1965.

A família Freire, assim como outros, é diretamente afetada pelas injunções do Golpe de Estado de 1964, da ditadura e do exílio político, que marcou e alterou drasticamente a história deles e do país, perdurando por dezesseis anos. Nesse período (1964/1980), os percursos de Elza Freire, entrelaçados aos de Paulo Freire, os mantêm vinculados aos desafios da Alfabetização de Adultos, residindo nas Américas e Europa, e envolvendo-se, em África, com os países recém-independentes da colonização portuguesa (SPIGOLON, 2014).

No início dos anos de 1980, após o retorno do exílio, findos os dias sombrios da ditadura militar com a abertura política instalada no país (BAUER, 2012; FERNANDES, 1975; GORENDER, 1987; REZENDE, 2001), o casal fixa residência em São Paulo e lá continua suas atividades político-pedagógicas, no campo da Educação, até 1986, quando Elza Freire falece, o que representou perda e saudade, profunda dor.

Por entre o escrito e o dito, surge Elza Freire, em pequenos trechos significativos de uma resumida cronologia, que visa mais as experiências do que os resultados. Para isso, enfatizo a tentativa de esquivar-me de uma espécie de ilusão e do "relato apaixonado", buscando desenvolver, pelos fatos, "um conjunto coerente e orientado" (BOURDIEU, 1998, p. 184). Ainda que, neste caso, seja necessário reconhecer que, em muitos momentos, as objetividades fundantes da pesquisa se mesclaram à subjetividade da pesquisadora. No decorrer dos processos, Elza Freire nos conduz e se deixa conduzir, o que estabelece e permite a relação e a conexão entre a objetividade do mundo real e a subjetividade do ser que as realiza.

O não escrito e o não dito, o silêncio, os ruídos e as angústias buscam lugares de escu- 
ta. Segundo Mazza e Zamboni, há uma permanente interação entre o vivido e o aprendido, o vivido e o transmitido e isto impacta sobremaneira o oficio do professor (MAZZA; ZAMBONI, 2015, p. 33).

Escrever ou não, dizer ou não, são também maneiras de provocar memórias e rememorações sobre Elza Freire que, ao escolher ser professora por si mesma, me fez, anos depois, escolhê-la sujeito que regula e configura as temporalidades da pesquisa.

\section{"Escritos Íntimos"}

Às vezes, por ir mais rápido não se faz história e aqui o que se busca fazer é história porque é isso que fica, quando formos embora.

Elza Freire (apud ORNELAS, 1987, tradução nossa)

A delicada e difícil questão a refletir sobre a memória não reside naquilo que é possivel rememorar, mas em saber lidar com o silêncio, a lembrança, o esquecimento...

O silêncio não é esquecimento, e a memória deve ser entendida, sobretudo, como fenômeno individual, coletivo e social, submetido às flutuações, transformações e mudanças constantes (POLLAK, 1989; 1992).

Se há forças que provocam o enfraquecimento da arte de narrar, enquanto discurso vivo, também tais forças fazem aparecer uma nova beleza ao que está desaparecendo (BENJAMIN, 1985).

Há o alinhavo do passado, presente e futuro, como expressões de uma arte da memória, individual e coletiva, permeada pela experiência sensivel (LARROSA, 1996; 2002).

Ancorei-me nas narrativas da memória e, como em toda memória, entrecruzam-se o objetivo e o subjetivo; o registro e a criação; a lembrança e o esquecimento; o silêncio e o dito; não seria diferente, pois, com os "Escritos Íntimos" de Elza Freire.
Os "Escritos Întimos" por mim assim denominados compõem o conjunto de fontes resguardando o campo de pesquisa que, desde 2006, venho constituindo, ao reunir materiais, acervos e arquivos em torno da temática Elza Freire. Eles são constituídos a partir das fontes, ${ }^{4}$ documentais e não documentais; fontes primárias, oficiais e não oficiais, escritas e orais; iconográficas e também filmografias, discografias, poesias, gravuras, cartas etc.

Esse conjunto de "Escritos Íntimos" constituem aportes investigativos. Ao manuseá-los foi possivel um levantamento preliminar, a partir da catalogação, sistematização e digitalização de página por página, agrupados até o momento em: caderno de receitas, agendas, cadernetas, papéis avulsos, manuscritos... são frutos das minhas coletas de dados e coleções de fontes, que desnudam, por exemplo: escolhas, intenções, sentidos e ideias de Elza Freire, e se inserem como recurso analítico, descritivo e interpretativo do sujeito que deles emerge.

É ainda impreciso o inventário, a abrangência e a profundidade deste material, tendo em vista garantir a problematização dos elementos, dos fatos, dos fragmentos e dos diversos registros, além de ser um instrumento para lidar com indicadores de classe social, condições econômicas, patrimônio cultural, dentre outros.

Há neles, citações, com nomes, referências a livros, grifos, rabiscos, abreviações, ideias entrecortadas, sentimentos interrompidos, reflexões e inflexões, colagens com gravuras, receitas culinárias... Destacadamente, os "Escritos İntimos" demonstram como os corpos e os papéis foram guardando e transformando as experiências.

4 A pesquisa realizou-se e se realiza com base em fontes e dados de natureza variada, portanto, considero fontes primárias aquelas coletadas diretamente pela pesquisadora no campo da pesquisa e que são alvo de descrição, análise e apresentação pública, pela primeira vez, incluindo: depoimentos, documentos, fotos pessoais, e os "Escritos Íntimos". 
De acordo com Mazza (2013), é essa uma das questões que os "Escritos Întimos" de Elza Freire nos colocam. Vemo-nos diante de um acesso privilegiado por uma cronologia que, na polifonia de sentidos, embaralha passado, presente e futuro, na acepção de potencializar esse sujeito, a partir das teias estabelecidas com o real multifacetado.

0 que se tentou foi ir, delicada e dedicadamente, colocando fragmentos dos "Escritos Íntimos" de Elza Freire, sobrepostos a outras narrativas, dentro da periodicidade da pesquisa e dos recortes analíticos, uma vez que reconheço a impossibilidade de conseguir trazê-los na forma de um capítulo à parte ou algo semelhante. Assim, penso que os deslocamentos para tê-los como parte das intertextualidades, como fontes de pesquisa, são possibilidades de diálogo e discussão na apresentação do sujeito, na composição das situações, das configurações e dos cenários dos quais Elza Freire emerge.

$\mathrm{Na}$ escolha dos trechos, tentei fazer com que a Educação - uma vez que constitui campo de meu interesse, agisse como permeio para os demais campos -, e seguisse sendo o mote para o envolvimento de Elza Freire e do casal, na problemática social e educacional, nas questões existenciais e nas visões de mundo. Nesse sentido, além de resguardar os sujeitos e realizar o entrecruzamento entre eles, levei em consideração os elementos que identificassem temáticas político-pedagógicas recorrentes, e aquelas que me ajudassem a dar visibilidade a esta mulher, explicitando eixos coletivos e individuais.

Trabalhei as narrativas da memória ao lado de um extenso mapeamento bibliográfico, como possibilidades de acessar processos, experiências, vivências e (re)construir percursos, mediatizados por singularidades e generalidades. É como somos capazes de imaginar, interpretar, criar, para contar, narrar, lembrar.
El tiempo de nuestras vidas es, entonces, tempo narrado; es tiempo articulado en una historia; es la historia de nosotros mismos tal como somos capaces de imaginarla, de interpretarla, de contarla y de contar(nos)la [...] Y es así, como narración, que cada punto del camino contiene todo el camino. [...] Por eso, en tanto que narrador, el caminante se contiene a sí mesmo en toda la extensión de caminar su camino. ${ }^{5}$ (LARROSA, 1996, p. 467-468)

Tempos da minha vida que, por aquelas páginas, se mesclaram aos tempos da vida de Elza Freire... Por caminhos que, ao trazer os "Escritos Întimos" para as análises iniciais, respeitei seus processos e não me detive em prováveis datas de produção. Procurei, no trato com eles, cativá-los no tocante à sobreposição das fontes, para que umas às outras, não se ofuscassem. Em muitos momentos, eles falam por si, ganham corpo e ocupam espaços.

É como se, ao lidar com eles, trabalhasse com a alquimia de elementos muito potentes, entremeados por temáticas igualmente fortes. Darei continuidade à abertura dos "Escritos Întimos" que, em situações oportunas, virão de novo à tona, pois a opção é trazer fragmentos desses manuscritos, na tentativa ousada de não decifrá-los, e sim se aproximar dos sentidos e significados neles contidos.

Sentidos e significados neles contidos que ganham contornos diversos e apontam que a condição da mulher é ainda mais limitada, apagada, estando arquivada nos "Escritos Íntimos". Cada um, a sua maneira, vai experienciando, e, como pode, arquivando a própria vida. Ou seja,

Não arquivamos nossas vidas, não pomos nos-

5 O tempo de nossas vidas é, então, tempo narrado; ele é articulado em uma história; é a história de como somos e tal como somos capazes de imaginá-la, de interpretá-la, contá-la e de nos contá-la [...] E assim, como narrativa, que em cada ponto do caminho contém todo o caminho. [...] Portanto, como um narrador, o próprio caminhante contém em si mesmo em toda a extensão de caminhar seu caminho. (LARROSA, 1996, p. 467-468, tradução nossa) 
sas vidas em conserva de qualquer maneira [...] fazemos um acordo com a realidade, manipulamos a existência: omitimos, rasuramos, riscamos, sublinhamos, colocamos em exergo certas passagens. [...] não só escolhemos alguns acontecimentos, como os ordenamos numa narrativa; a escolha e a classificação dos acontecimentos determinam o sentido que desejamos dar às nossas vidas. (ARTIÉRES, 1998, p. 3-4)

Essa referência, ou seja, a "narrativa" de partes significativas da sua história, das experiências com a Educação e com a Educação de Adultos, dos anos ao lado de Paulo Freire, e o arquivamento da própria vida abrem possibilidades de análise que passam a ser importantes para os processos do sujeito, tendo em vista que é através dos "acontecimentos da vida" que ele apresenta reflexões acerca de si mesmo, do outro e das relações estabelecidas entre eles e o mundo.

\section{Os manuscritos: sentidos vividos}

Para entender tem que saber sentir [...] Conceito representação abstrata do concreto [...] A prática sobre o mundo [...] A consciência é que faz a realidade [...] Estimular a liberdade do uso da criatividade [...] Cada 1 tem a sua angústia [...] A briga é contra o capitalismo [...] A melhor maneira de realizar o possivel é começar realizando hoje o impossível [...]A importância da História na luta dos oprimidos [...] Humildade para colocar as coisas. Se perder a sensibilidade podemos morrer.

Elza Freire (Cadernos de receitas, s/d, s/ed, Escritos Íntimos)

As memórias de Elza Freire contidas nos "Escritos Íntimos" são memórias da Educação e dos períodos em que ela foi partícipe. São silêncios, lembranças, esquecimentos, ideias e imagens - apaixonadas e comprometidas, políticas e pedagógicas, críticas e reflexivas. São

Figura 1 - Caderno de receitas de Elza Freire, escritos e colagens, seus "Escritos Íntimos".

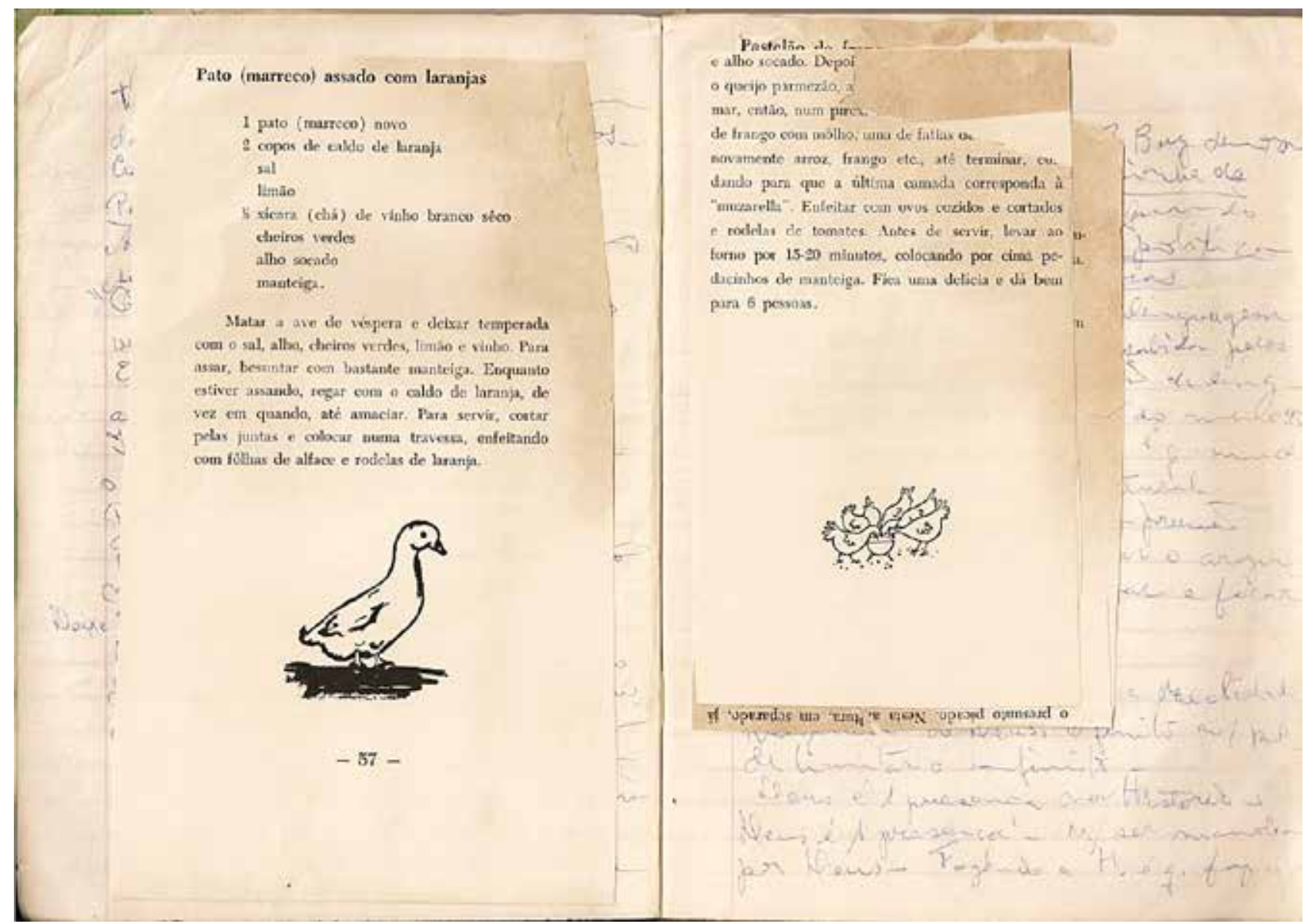

Fonte: Acervo pessoal de Madalena Freire, cedido à pesquisadora, disponível em Spigolon (2014, p. 419). 
leituras de realidade, de mundo e de vida. São narrativas soltas para que não se torne imemorável.

Memórias que se manifestam em espaços, lugares e tempos, públicos ou privados, que se expressam pelo sujeito, por suas vozes, mãos, experiências, por seus percursos, conceitos e deslocamentos, por suas questões existenciais, relacionais, emocionais.

Os "Escritos Întimos" de Elza Freire também são contraditórios e paradoxais, à medida que escondem e revelam suas interpretações acerca do movimento e processo político, das relações e das posições assumidas, tanto pela nação quanto pela igreja e a CNBB. Ela, assim como elas, se contradiz e é paradoxal: posiciona-se criticamente, tece comentários políticos, analisa conjunturas, cita nomes, escreve reflexões, grifa, abrevia, expressa pensamentos, imprime sentimentos, para depois colar receitas, dentre elas: Pato (marreco) assado com laranjas e Pastelão de frango.

Figura 2 - Caderno de receitas de Elza Freire. "Escritos Íntimos”.

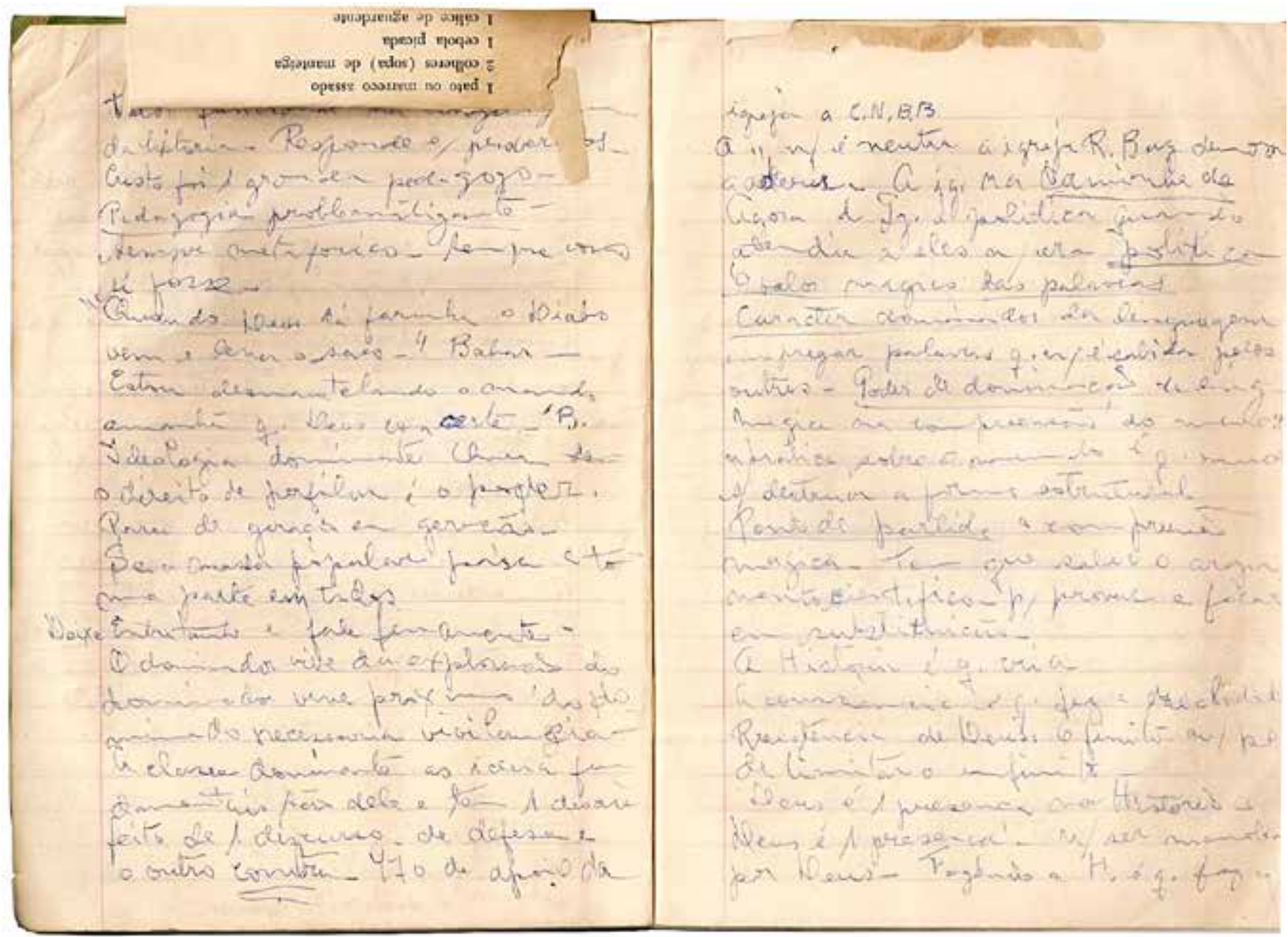

Fonte: Acervo pessoal de Madalena Freire, cedido à pesquisadora, disponível em Spigolon (2014, p. 420).

[...] 470 de apoio da Igreja à CNBB. A igreja não é neutra... A Igreja na caminhada. A Igreja é política... Deus é uma presença na História... Não ser manobrado por Deus... Fazendo História é que faz o reino... A palavra de Deus deve ser recriada... As possibilidades de enfrentar o dominador. 0 discurso legitimando a ação dominadora. A defesa do Nordeste. A ação do ingênuo, ele não tem a possibilidade de derrubar a verdade. Ele acredita na possibilidade de uma ação de massa. O crescimento da miséria, diz que é ignorante, indolente - A briga é contra o capitalismo. Capitalismo se moderniza. O Estado militar dá suporte ao capitalismo. Os dominadores estão usando a cultura... Ritmo popular com letra nova Capitalismo é um sistema econômico, polí- 
tico e social - ele espolia o produto do trabalho e aliena o produtor do trabalho. É dialético - a classe dominante... Não é pura alienação não é mecânico... Tanto quanto se pode diminuir o custo social, devemos evitar - cedo ou tarde temos que enfrentar - processo conflitivo, o outro lado tenta calar. Os opressores é quem provoca a violência. Apaziguar os ânimos... Arrancar meios de lutas. Fazer tudo possivel de solidariedade... A Igreja estava ao lado do poder, em grande parte está com o golpe, a marcha da família. Dona Pátria e família CNBB apoia o golpe. A maioria dos padres estrangeiros deram apoio - à medida que eles iam vendo o único espaço em que era possivel falar - a ouvir o povo iam se despojando do elitismo e o povo reeducou os Padres e Freiras. A História exigiu que tudo se transformasse. 0 profeta D. Helder, a Igreja profética é tão antiga quanto a mensagem antiga e nova quanto a mensagem Cristã. Na História o papel da Igreja que virou profética. Espaço histórico brasileiro. $E$ foi no Nordeste que se deu - a gente faz a História... A Igreja brasileira foi a instituição que mais avançou pelo poder que ela tem - a consciência política nova dos outros brasileiros... Aproveitar como fermento na transformação política do país. Processo da leitura de redescoberta. A violência completamente boba - que um país é invertido, as pessoas matam... A luta de grupos dominados contra os dominadores - Direito de defesa, o uso da força em favor da justiça tem um valor - usar a força para restaurar a paz... Conflitos internos com as classes sociais... 0 ato de Rebeldia que se instaura. Nordeste cabo do mundo. Niveis de percepção... CNBB os bispos eram minoria a voz progressista era pouca e foi crescendo. Dom Luciano deu a interferência papal, mostra ao povo que não há divergência, exemplo que não deva ser modelo mais o procedimento agora foi político interno não opção da Igreja CNBB. Necessária solidariedade Humana (Elza Freire, caderno de receitas s/d, s/ed, Escritos Íntimos, grifos da autora, disponivel em SPIGOLON, 2014, p. 419-420).

Há que se aprofundar as relações entre igreja e política. Há que se aprofundar essas relações e a Educação. Enquanto isso, que inferências podemos fazer destes "Escritos Întimos"?
A sutileza de conseguir encontrar Elza Freire - indicando situação ou condição em meio ou dentro de memórias, dentro de si, de páginas pautadas. Uma mulher escondida ou protegida por debaixo de receitas cortadas, coladas e recortes sobrepostos... Uma mulher encontrada e guardada num caderno de receita... Uma mulher encontrada por outra mulher.

E que se desvela... Destaco o desarquivar dos "Escritos Íntimos" de Elza Freire, como parte da realização do campo empírico, que avança por divulgar e analisar preciosidades históricas, no tocante à Educação e à de Adultos, por exemplo:

[...] O homem que aprendeu para poder pegar o homem que enganava o trabalhador [...] Encontra as palavras geradoras. Temos o seguinte: geradora na medida que possibilita a feitura de outras palavras [...] o conhecimento viabilizador para os sentidos [...] O sentir uma certa materialidade pela sensibilidade - a percepção do objeto - registra certas percepções - pego - sinto - percebo - falo o nome do objeto [...] Alfabetizar é montar o sistema de valores escritos, esta montagem tem que ter [...] A alfabetização é um ato político [...] Alfabetização criadora e libertadora - ele discute a sua palavra e a frase [...] (Elza Freire, caderno de receitas $s / d$, s/ed, Escritos Íntimos, disponivel em SPIGOLON, 2009, p. 163).

Ao trazer esses fragmentos e manuscritos que, de certa forma, descrevem o suporte dos "Escritos Íntimos", re-escrevo a forma dessa mulher se expressar, por meio das linguagens, das imagens, e se esconder, talvez resguardarse, por meio das colagens.

Ao examinar o conteúdo e a natureza do material, articulo o teórico-metodológico ao campo empírico, evidenciando as contribuições e influências de Elza Freire, na elaboração, sistematização e fundamentação do Método Paulo Freire, compondo a documentação do período. As análises dos "Escritos Íntimos" deixam evidenciar a descrição das realidades 
político-pedagógicas e explicar fragmentos do pensamento e das ações dela como sendo ele- mentos constitutivos dos trabalhos desenvolvidos pelo casal Freire.

Figura 3 - Caderno de receitas de Elza Freire. "Escritos Íntimos".

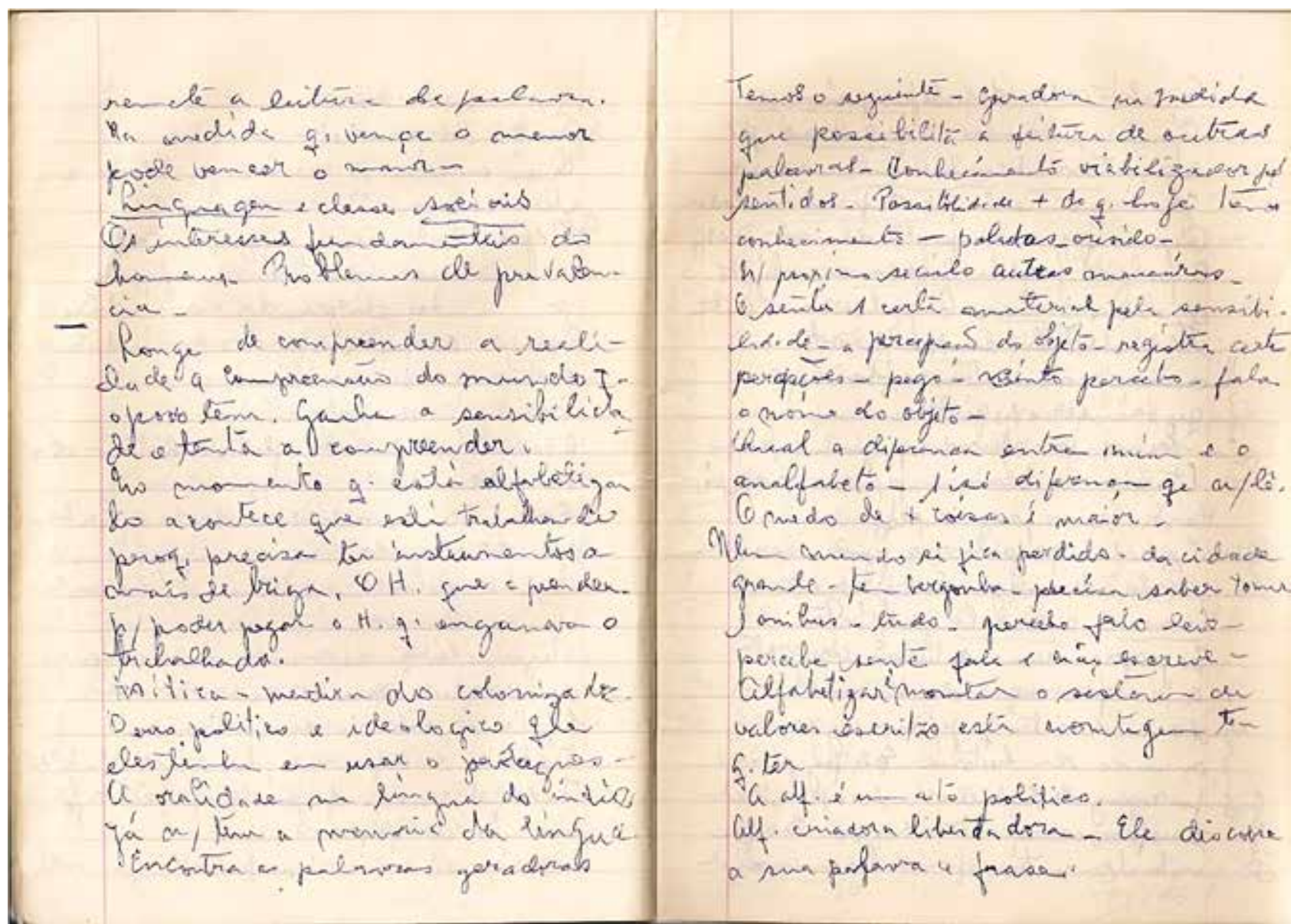

Fonte: Acervo pessoal de Madalena Freire, cedido à pesquisadora, disponível em Spigolon, 2009, p. 163.

São registros em torno da Educação brasileira, por meio da sistematização das primeiras experiências com a Educação de Adultos, nos registros de Elza Freire. Fontes primárias trazem, às novas gerações, possibilidades de consultar materiais que tornem públicos o fomentar e o ampliar as discussões posteriores.

As filigranas dos "Escritos Întimos" têm vida própria, manifestam-se por si:

A Reflexão e teoria... Liberdade do uso da criatividade... Há ordem e disciplina... Como eu vejo o mundo? Medo de mostrar a emoção... Ninguém navega na história de repente... A melhor maneira de realizar o possivel é começar realizando hoje o impossivel... Aproveitamento das formas de cultura popular. A expressão cultural tem vida própria se apossa de uma expressão da cultura. Transformar as expressões culturais. É importante penetrar na questão para compreender a cultura... Profundo significado da vida que continua. Expressão de fé e cultura... Avaliação da nossa prática, capacidade de abstrair, vivenciando o processo, cada um tem a sua angústia... Prática educativa nenhuma que o educador se ponha á frente do educando. É permanente algo que se ensina. É dialético. Tem ensinante e aprendiz. Na escola é sistematizado, em casa asistematizado. Não negar o conhecimento que se transfere. Aprender a aprender. Teoria do conhecimento. Humildade para colocar as coisas. Se perder a sensibilidade podemos morrer (Elza Freire, caderno de receitas s/d, s/ed, Escritos Íntimos, disponivel em SPIGOLON, 2014, p. 433-434).

"Escritos Íntimos" que, aos poucos, vão sendo apresentados, dados a conhecer, por 
quem os coligiu, recebeu e, ao the serem assim confiados, tenta organizá-los, dentro de uma lógica de pesquisa eivada por objetividades, subjetividades e rigor acadêmico. Há dores e amores, indagações e questões nas ciências, talvez só os mais sensiveis possam perceber, tentando dar a eles, enquanto pesquisadores, o trato e o patamar que podem receber.

É a dimensão do humano e da humanidade. Enquanto humanos "somos inteireza" e, como diz Madalena Freire, “inteireza, marcada por dimensões que nos constitui numa totalidade; somos constituídos de cognição, razão, inteligência, mas também de afeto, amorosidade" (2008, p. 24-25). E também Elza Freire: “a gente só não vive, mais tem a cultura [...] a consciência é que faz a realidade [...] para entender tem que saber sentir" (caderno de receitas, s/d, s/ ed, Escritos Íntimos).

Entender, sentir, se permitir a identificar e extrair materiais dos "Escritos Íntimos", que orientam e conduzem análises iniciais, por exemplo:

[...] Pedagogia do povo; Pedagogia problematizante; Política cultural; Conceito representação abstrata do concreto; Caráter dominador da linguagem; Aprender a re-aprender; Metodologia da libertação; Arqueologia da dor; Reprodução da prática social; Intimidade com rigor científico; Pesquisar no nível do cotidiano; Avaliação e vivência do processo; Psicologia de grupo; Relação afetiva do dominado e do dominador; Discurso legitimador; Habilidade artesanal; A história nas mãos; Experiência e processo da luta; Paixão - ciência - rigorosidade; Forma dos ritos; Conhecer é refazer; Leitura da palavra e leitura do mundo; Momento da realidade; Problemas de prevalência; Palavras geradoras; Alfabetização criadora libertadora; Alfabetizar é um ato político; Forma poética e sensibilidade para entender o povo; Violência histórica; Emoção e emotividade; Respeito ao processo histórico; Diálogo entre oprimido e opressor; Reflexão; Transformação política do país; Ato de rebeldia; Percepção do mundo; Globalidade do fonema; Codificar e descodificar; Círculo no mundo; Conhecimento aplicado à prática; Conjunto universal para todos; Nunca castrar a criação; Tema gerador; Observações em torno do contexto; Charlatões da nova Pedagogia; Visão política; Estrutura de consciência; A arte do fazer; Pensamento dialético; $O$ conceito de práxis em Marx; A política contra a privacidade; Compreensão ampla do sujeito [...] (Elza Freire, caderno de receitas s/d, s/ed, Escritos Íntimos).

O fato é que os "Escritos Íntimos" não apresentam um estofo de discussões estruturadas e nem ganham a forma de um texto acabado com ideias elaboradas - eles lembram um turbilhão de ideias que são a erupção de uma potência, sem tempo e sem espaço para os devidos acabamentos, são palavras expelidas abrupta e originalmente.

Será que os "Escritos Íntimos" revelam e escondem uma mulher que, na sombra das esferas pública e privada, guardava uma energia contida que buscava/faltava formas e lugares para manifestar-se? Será que eram marcas da educação familiar tradicional nordestina? Da condição de mulher? Da percepção das possibilidades de desintegração da família, nos contextos de ditadura e de exílio? Será que eram medos, inseguranças e timidez? Será inquietação, renúncia, ponderação? o que será que será?

Levanto as questões e aponto que Elza Freire não quis disputar os espaços públicos com Paulo Freire, e que construiu com ele uma proposta político-pedagógica que revoluciona o mundo, desde 1950, e que continua revolucionária e contemporânea.

Concomitante ao movimento das páginas dos "Escritos Íntimos", é possível compreender as mediações político-pedagógicas de Elza Freire e Paulo Freire, que propõe que a leitura do mundo preceda a leitura da palavra (FREIRE, 1992, p. 11).

É uma leitura da vida, seguida pela leitura do mundo e das palavras, das condições concretas que ajudaram a gerar as experiências 
do vivido, do pensado e do sentido, do escrito e do dito, até as propostas político-pedagógicas do casal Elza Freire e Paulo Freire.

Examinar com atenção e cuidado as páginas dos "Escritos Íntimos" de Elza Freire - como percursos de vida e como estes percursos produziram uma memória e um sentimento sobre e a partir de, com, como... levando inclusive à produção de práxis - pensamentos mais ação, é ao mesmo tempo incorrer em uma leitura da palavra, do mundo e da vida.

Que mulher é esta que se revela e se esconde nas páginas de um caderno de receitas? Que mulher é esta que faz bricolagem com palavras, gravuras, receitas e recortes de revistas? Que mulher é esta que foi professora, diretora de escola, mãe e esposa, companheira, mulher de Paulo Freire?

\section{Nas entrelinhas finais}

Fazer memórias é um pouco recriar o que foi feito [...].

Freire e Guimarães (2002, p. 35)

Escrevo reconhecendo que há muito por fazer e muito não foi feito. Porém, considero que o que está sendo apresentado abre perspectivas para trabalhos vindouros e se aproxima de uma compreensão mais alargada acerca de materiais de pesquisa como os "Escritos Íntimos", de Elza Freire, estabelecendo condições investigativas e chaves de interpretação, com conexões de sentido pensadas enquanto emoções, cognições, percepções teóricas, anotações práticas.

Fazer memórias em torno de Elza Freire (e de Paulo Freire também) é recriar a Educação, a docência, a atuação profissional, a vivência da teoria e da práxis; é encontrar na narrati- va um instrumento para raciocinar sobre contextos, ler realidades, compreender mundos, aproximar-se de mim e do outro, transformar a sociedade; é parte do referencial teóricometodológico, através de fatos contidos nas fontes, a fim de assumirem significados e sentidos, tendo em vista a produção de conhecimentos.

A importância de se ouvir a voz do professor (GOODSON, 2005) e de ler a palavra do professor - Elza Freire foi professora, associa a escuta e a escrita do pesquisador, como possibilidade de aprendizagem sobre o passado e sobre o presente. Destaca a potencialidade das narrativas para o "empoderamento" do sujeito, na medida do processo dialógico e colaborativo que se constrói entre eles.

Quer dizer, essas categorias ajudam a pensar Elza Freire como um sujeito que, epistemologicamente, ou seja, por meio da relação sujeito, realidade e conhecimento, em momentos da sua vida, nos fatos, fragmentos e nos "Escritos Íntimos", retomou seus percursos, suas memórias, ressignificando o passado no presente, e perspectivando diferentemente 0 futuro.

Inventariar fontes de pesquisa como essas é tarefa que se realiza com surpresas e sobressaltos. Acondicionadas em um caderno de receitas desencapado e arrematado por recortes de revistas ou papéis avulsos, guardados em páginas amareladas pelo tempo, estas fontes exigem um folhear ziguezagueante de quem busca com método colocar ordem na desordem que é a vida, e na passagem vertiginosa pela vida. Resistentes, elas perturbam e seduzem, enquanto são descobertas, tocadas, retomadas, expostas. São escritas de si em "Escritos Íntimos" de Elza Freire. 


\section{Referências}

ARTIÉRES, Philippe. Arquivar a própria vida. Revista

Estudos Históricos, v. 11, n. 21, p. 09-34, 1998.

BAUER, Carlos. A natureza autoritária do Estado no Brasil contemporâneo. Elementos de história e questionamentos políticos. São Paulo: José Luís e Rosa Sundermann, 2012.

BENJAMIN, Walter. O narrador: considerações sobre a obra de Nikolai Leskov. In: Magia e técnica, arte e política (Obras escolhidas, Vol. 1). Trad. Sérgio Paulo Rouanet. São Paulo: Brasiliense, 1985. p. 197-221.

BOURDIEU, Pierre. A ilusão biográfica. In: AMADO, Janaína; FERREIRA, Marieta de Moraes. (Orgs.). Usos e abusos da História Oral. Rio de Janeiro: FGV, 1998. p. 183-191.

BRÜHL, Dieter. Método científico e objeto nas ciências sociais: algumas reflexões sobre o caráter dialético do processo de pesquisa em Ciências Sociais. s/d; s/ed. (mimeo).

FERNANDES, Florestan. A revolução burguesa no Brasil: ensaio de interpretação sociológica. Rio de Janeiro: Editora Jorge Zahar, 1975.

FREIRE, Elza. Setembro de 1977. In: COSTA, Albertina de O. et. alii. (Orgs.). Memórias das mulheres do exílio. Rio de Janeiro: Paz e Terra, 1980. p. 200-206.

Caderno de receitas, s/d; s/ed. Manuscritos.

In: Escritos Íntimos. Acervo pessoal de Madalena Freire, cedido à pesquisadora.

FREIRE, Madalena. Educador, educa a dor. São Paulo: Paz e Terra, 2008.

FREIRE, Paulo. A importância do ato de ler: em três artigos que se completam. São Paulo, Cortez: 1992. ; GUIMARÃES, Sérgio. Aprendendo com a própria história. v. II. Rio de Janeiro: Paz e Terra, 2002.

GOODSON, Ivor. Representing teachers: brining teachers back in. In: GOODSON, Ivor. Learning, curriculum and fife politics - the selected Works of Ivor Goodson. New York: Routledge; Taylor \& Francis Group, 2005. p. 211-221.
GORENDER, Jacob. Combates nas trevas. A esquerda brasileira: das ilusões perdidas à luta armada. São Paulo: Ática, 1987.

LARROSA, Jorge. Notas sobre a experiência e o saber da experiência. Revista Brasileira de Educação: Rio de Janeiro, n, 19, p. 20-30, 2002.

Narrativa, identidad e desidentificación. In: LARROSA, Jorge. La experiencia de la lectura. Estudios sobre literatura e formación. Barcelona: Laertes S.A de Ediciones, 1996. p. 461-482.

MAZZA, Débora; ZAMBONI, Ernesta. Memória, silêncio, esquecimento, potência. In: PAULILO, André Luís. (Org.). A docência e a memória: escritas e lembranças da educação. Campinas, SP: Edições Leitura e Crítica; ALB, 2015. p. 17-38.

. Orientação de pesquisa/DO, 2013, Campinas, Brasil. 18 de janeiro e 20 de agosto.

ORNELAS, Arturo. Elsa Maia Costa de Oliveira, Elsa Freire. Cuernavaca, México, 1987. Datilografado, cedido à pesquisadora.

POLLAK, Michael. Memória esquecimento e silêncio. Estudos Históricos, v. 2, n. 3, p. 200-212, 1989.

. Memória e identidade social. Estudos Históricos, v. 5, n. 10, p. 200-215, 1992.

REZENDE, Maria J. de. A ditadura militar no Brasil: repressão e pretensão de legitimidade 1964-1984. Londrina: UEL, 2001.

SPIGOLON, Nima I. Pedagogia da Convivência: Elza Freire - uma vida que faz Educação. 2009. 264 f. Dissertação (Mestrado em Educação) - Programa de Pós-Graduação, Universidade Estadual de Campinas - UNICAMP, Campinas, 2009.

As noites da ditadura e os dias de utopia o exílio, a educação e os percursos de Elza Freire nos anos de 1964 a 1979. 506 f. Tese (Doutorado em Ciências Sociais na Educação) - Programa de PósGraduação, Universidade Estadual de Campinas UNICAMP, Campinas, 2014.

Recebido em: 03.05.2016

Aprovado em: 28.07.2016 
Nima Imaculada Spigolon é Mestre em Educação e Doutora em Ciências Sociais na Educação pela Universidade Estadual de Campinas (UNICAMP). Professora da Faculdade de Educação (FE) da UNICAMP, credenciada no Programa de PósGraduação em Educação dessa universidade. Coordenadora do Grupo de Estudos e Pesquisas em Educação de Jovens e Adultos (GEPEJA) e pesquisadora do Grupo de Estudos e Pesquisas em Políticas Públicas e Educação (GPPE), ambos da FE/UNICAMP. e-mail: professoranima@gmail.com.

Rua Aliomar Baleeiro, 209. Cidade Universitária II. Campinas/SP CEP: 13.083-020 